\title{
World Allergy Organization survey on global availability of essentials for the assessment and management of anaphylaxis by allergy-immunology specialists in health care settings
}

\author{
Simons, F E R ; World Allergy Organization
}

\begin{abstract}
BACKGROUND: The availability of anaphylaxis guidelines and of medications, supplies, and equipment for the assessment and management of anaphylaxis by allergy-immunology specialists in health care settings worldwide is unknown. OBJECTIVE: To ascertain the global availability of these essentials. METHODS: A survey instrument was developed and sent by e-mail in 2008 to a nonrandomized convenience sample of representative leading allergy-immunology specialists in 52 countries identified through the World Allergy Organization. Responses were analyzed by country. RESULTS: Surveys were returned from 44 of 52 countries on 6 continents, for an $85 \%$ response rate. Anaphylaxis guidelines were reported to be in use in $70 \%$ of the 44 responding countries. The diagnosis of acute anaphylaxis was reported to be based on clinical history and physical examination alone in $63 \%$ of responding countries. Medications for anaphylaxis treatment were reported to be available in the 44 responding countries as follows: epinephrine (adrenaline) for injection, 100\%; any intravenous glucocorticoid, 89\%; any intravenous H1antihistamine, $77 \%$; any intravenous $\mathrm{H} 2$-antihistamine, $70 \%$; glucagon, $73 \%$; atropine, $73 \%$; dopamine, 86\%; noradrenaline, 70\%; vasopressin, 64\%; and a beta 2-agonist for nebulization, 86\%. Supplies and equipment for anaphylaxis treatment were reported to be available in responding countries as follows: for giving supplemental oxygen, 95\%; for intubation, 89\%; for giving intravenous fluid resuscitation, $91 \%$; for monitoring oxygenation using pulse oximetry, 91\%; and for continuous noninvasive blood pressure and cardiac monitoring, 81\%. CONCLUSIONS: Allergy-immunology specialists reported that except for epinephrine ampules life-saving essentials for the assessment and management of anaphylaxis in health care settings were not universally available worldwide in 2008.
\end{abstract}

DOI: https://doi.org/10.1016/j.anai.2010.01.023

Posted at the Zurich Open Repository and Archive, University of Zurich ZORA URL: https://doi.org/10.5167/uzh-43145

Journal Article

Originally published at:

Simons, F E R; World Allergy Organization (2010). World Allergy Organization survey on global availability of essentials for the assessment and management of anaphylaxis by allergy-immunology specialists in health care settings. Annals of Allergy, Asthma Immunology, 104(5):405-412.

DOI: https://doi.org/10.1016/j.anai.2010.01.023 


\title{
World Allergy Organization survey on global availability of essentials for the assessment and management of anaphylaxis by allergy- immunology specialists in health care settings
}

\author{
F. Estelle R. Simons, MD, FRCPC, ${ }^{*}$ for the World Allergy Organization
}

Background: The availability of anaphylaxis guidelines and of medications, supplies, and equipment for the assessment and management of anaphylaxis by allergy-immunology specialists in health care settings worldwide is unknown.

Objective: To ascertain the global availability of these essentials.

Methods: A survey instrument was developed and sent by e-mail in 2008 to a nonrandomized convenience sample of representative leading allergy-immunology specialists in 52 countries identified through the World Allergy Organization. Responses were analyzed by country.

Results: Surveys were returned from 44 of 52 countries on 6 continents, for an $85 \%$ response rate. Anaphylaxis guidelines were reported to be in use in $70 \%$ of the 44 responding countries. The diagnosis of acute anaphylaxis was reported to be based on clinical history and physical examination alone in $63 \%$ of responding countries. Medications for anaphylaxis treatment were reported to be available in the 44 responding countries as follows: epinephrine (adrenaline) for injection, 100\%; any intravenous glucocorticoid, 89\%; any intravenous $\mathrm{H}_{1}$-antihistamine, 77\%; any intravenous $\mathrm{H}_{2}$-antihistamine, 70\%; glucagon, 73\%; atropine, 73\%; dopamine, 86\%; noradrenaline, 70\%; vasopressin, 64\%; and a $\beta_{2}$-agonist for nebulization, 86\%. Supplies and equipment for anaphylaxis treatment were reported to be available in responding countries as follows: for giving supplemental oxygen, $95 \%$; for intubation, $89 \%$; for giving intravenous fluid resuscitation, $91 \%$; for monitoring oxygenation using pulse oximetry, $91 \%$; and for continuous noninvasive blood pressure and cardiac monitoring, $81 \%$.

Conclusions: Allergy-immunology specialists reported that except for epinephrine ampules life-saving essentials for the assessment and management of anaphylaxis in health care settings were not universally available worldwide in 2008.

Ann Allergy Asthma Immunol. 2010;104:405-412.

\section{INTRODUCTION}

The worldwide burden of anaphylaxis, a severe, life-threatening generalized or systemic hypersensitivity reaction, ${ }^{1-3}$ is difficult to quantify. Although anaphylaxis is a high priority public health issue in some countries, it is still considered to be a rare disease in many other countries. The reported rate of occurrence appears to vary widely from one country to another. The lifetime prevalence has been estimated at $0.05 \%$ to $2 \%$ based on international studies. ${ }^{4}$

Affiliations: * Departments of Pediatrics and Child Health and Immunology, Faculty of Medicine, University of Manitoba, Winnipeg, Manitoba, Canada.

Disclosures: Dr. Simons holds funding from the Canadian Institutes of Health Research. She serves as an advisor to ALK-Abello, Dey, Intelliject, Lincoln Medical, and Sciele. She also serves on the Food Allergy and Anaphylaxis Network Medical Advisory Board. She is a contributing editor to The Medical Letter. She is a Section Editor and author in UpToDate.

Financial Support Disclosure: UCB provided a grant to the World Allergy Organization for this project.

Received for publication November 30, 2009; Received in revised form January 22, 2010; Accepted for publication January 29, 2010.

(C) 2010 American College of Allergy, Asthma \& Immunology.

Published by Elsevier Inc. All rights reserved.

doi:10.1016/j.anai.2010.01.023
To increase awareness of anaphylaxis, to help improve standards of care for the diagnosis and treatment of anaphylaxis worldwide, and to contribute to anaphylaxis education, global anaphylaxis guidelines are being developed by the World Allergy Organization (WAO). The WAO is an international federation of regional and national allergy and clinical immunology societies dedicated to advancing excellence in clinical care, research, education, and training in allergy and clinical immunology.

Ascertaining how anaphylaxis is defined, diagnosed, and treated around the globe is an important preliminary step toward development of the WAO anaphylaxis guidelines. We hypothesized that availability of national guidelines and of medications, supplies, and equipment for assessment and management of anaphylaxis in health care settings as reported by allergy-immunology specialists might vary considerably worldwide. We tested this hypothesis by conducting a survey of allergy-immunology specialists in the WAO.

\section{METHODS}

A survey instrument was designed to focus on the assessment and management of anaphylaxis by allergy-immunology specialists in health care settings (hospitals, clinics, and medical offices) worldwide, particularly with regard to availability of 
national anaphylaxis guidelines and of essential medications, supplies, and equipment. This survey, containing 14 multiplechoice, multipart questions in English, was sent by e-mail in 2008 to a nonrandomized, cross-sectional, convenience sample (in epidemiologic terms) of allergy-immunology specialists from 52 different countries, with the aim of obtaining 1 response per country. These physicians were among the leading allergy-immunology practitioners, teachers, and researchers in the world, as identified through the WAO House of Delegates, which at any given time contains a balanced representation of allergy-immunology specialists from all global regions and all countries where the specialty is established or is becoming formally established.

Translation of the survey was provided if needed. If no response to the initial e-mail survey was received, the e-mail address was vetted and the survey was re-sent in up to 4 follow-up e-mails.

The physicians were asked to focus on the country in which their clinical work in allergy-immunology was performed and to provide information about the definition of anaphylaxis in use and the anaphylaxis guidelines in use, if any. They were asked how the diagnosis of an acute anaphylaxis episode was made and to report on the availability of medications, supplies, and equipment for treatment of such episodes. There were specific questions about availability of medications such as epinephrine (adrenaline), $\mathrm{H}_{1}$-antihistamines, $\mathrm{H}_{2}$-antihistamines, $\beta_{2}$-adrenergic agonists, glucocorticoids, glucagon, atropine, dopamine, noradrenaline, and vasopressin.

The physicians were also asked about availability of oxygen and other supplies and equipment needed for airway management, intravenous fluids and other supplies and equipment for shock management, equipment for monitoring patients, and about the body position in which patients were placed during treatment. In addition, they were asked how patients discharged from a health care facility were prepared to manage anaphylaxis recurrences in the community, about availability of tests to confirm allergen sensitization, and about common triggers of anaphylaxis in their country.

In 4 instances in which 2 physicians responded from a country, 1 of the 2 responses was randomly selected for inclusion in the database. Responses were analyzed by country and expressed as percentage of countries from which a response to each specific question was received.

\section{RESULTS}

Surveys were returned from 44 of 52 countries on 6 continents, for a response rate of $85 \%$. The continents and countries represented were Africa and the Middle East (Egypt, South Africa, Lebanon, Israel), Asia (Bangladesh, China, India, Japan, South Korea, Malaysia, Singapore, Thailand, Vietnam), Europe (Austria, Bulgaria, Czech Republic, Denmark, France, Germany, Greece, Hungary, Iceland, Italy, Netherlands, Poland, Portugal, Romania, Russia, Serbia/ Montenegro, Spain, Switzerland, Turkey, Ukraine, United Kingdom), South America (Argentina, Brazil, Chile, Uru- guay, Venezuela), North America (Canada, Mexico, and the United States), and Australia and New Zealand.

Most physicians responding to the survey provided complete answers to each of the specific multipart questions. This is described throughout as "responses were received from 44 of the 52 countries" or "in/of the 44 responding countries." For 2 of the multipart questions, complete responses were received from only 43 of the 52 countries, and this is described in the "Results" section and tables as "responses were received from 43 of the 52 countries" or "in/of the 43 responding countries."

The definitions of anaphylaxis reported to be in use in the 44 responding countries, as summarized in Table 1, were the WAO definition ("anaphylaxis is a severe life-threatening generalized or systemic hypersensitivity reaction"); ${ }^{1}$ the European Academy of Allergology and Clinical Immunology (EAACI) definition, ${ }^{2}$ which is identical to the WAO definition; and/or the National Institute of Allergy and Infectious Disease/Food Allergy and Anaphylaxis Network (NIAID/ FAAN) definition ("anaphylaxis is a serious allergic reaction that is rapid in onset and may cause death"). ${ }^{3}$

National anaphylaxis guidelines, defined as those developed within the responding physician's own country, were reported to be in use in $36 \%$ of the 44 responding countries (Table 1). These guidelines were published in different languages and formats, including print medical journals, online medical journals, booklets, bulletins, circulars, protocols,

Table 1. Availability of National Anaphylaxis Guidelines and Definition of Anaphylaxis Used

\begin{tabular}{cc}
\hline Anaphylaxis definitions and guidelines & Responding \\
countries, \% \\
$(N=44)^{a}$
\end{tabular}

Definition of anaphylaxis used

World Allergy Organization definition $\quad 73$

NIAID/FAAN definition $\quad 36$

Other definitions (eg, EAACl definition) $\quad 7$

No definition

Anaphylaxis guidelines used ${ }^{\mathrm{a}, \mathrm{b}}$

National guidelines ${ }^{c}$

Other guidelines $^{d} \quad 34$

Both national and other guidelines $\quad 7$

Neither national nor other guidelines $\quad 30$

Abbreviations: EAACI, European Academy of Allergology and Clinical Immunology; FAAN, Food Allergy and Anaphylaxis Network; NIAID, National Institute of Allergy and Infectious Diseases.

a Numbers add up to more than $100 \%$ because more than 1 definition or guideline was used in some countries.

b Guidelines, in any language or format, as defined by the responders.

c Guidelines developed in the responder's country.

d Guidelines developed in a country other than the responder's, most commonly the Anaphylaxis Practice Parameter of the American Academy of Allergy, Asthma, and Immunology and the American College of Allergy, Asthma, and Immunology, but also the guidelines of the Resuscitation Council (United Kingdom) or the Australasian Society of Clinical Immunology and Allergy. ${ }^{5-7}$ 
and/or Web sites. ${ }^{5-14}$ They varied in scope and comprehensiveness. "Other" anaphylaxis guidelines, ${ }^{5-7}$ defined as those developed in a country different from the responding physician's own country, were in use in $34 \%$ of the 44 responding countries (Table 1). No anaphylaxis guidelines were reportedly used by allergy-immunology specialists in $30 \%$ of the responding countries.

In $63 \%$ of 43 responding countries, the diagnosis of acute anaphylaxis was reported to be based on clinical history and physical examination alone. Laboratory tests, such as measurement of serum total tryptase levels or plasma or 24-hour urine histamine levels, were available to confirm the clinical diagnosis in only $37 \%$ of the responding countries.

For the management of an acute anaphylaxis episode, epinephrine (adrenaline) in ampule formulations for injection by any route was reported to be available in all of the 44 responding countries (Table 2). One or more intravenous glucocorticoids and 1 or more intravenous $\mathrm{H}_{1}$-antihistamines, as well as an inhaled $\beta_{2}$-adrenergic agonist by nebulizer and compressor, were available in many, but not all, countries. An intravenous $\mathrm{H}_{2}$-antihistamine, glucagon, atropine, dopamine, noradrenaline, and vasopressin were not universally available. All the basic medications considered to be necessary, as defined by expert opinion ${ }^{5,6}$ (injectable epinephrine, glu-

Table 2. Availability of Medications for Acute Anaphylaxis Treatment

\begin{tabular}{|c|c|}
\hline Medication & $\begin{array}{l}\text { Responding } \\
\text { countries, \% } \\
(\mathrm{N}=44)\end{array}$ \\
\hline Epinephrine (adrenaline) ampules ${ }^{a}$ & 100 \\
\hline \multicolumn{2}{|l|}{ Other medications } \\
\hline Glucocorticoid ${ }^{\mathrm{b}, \mathrm{c}}$ (any intravenous formulation) & 89 \\
\hline $\begin{array}{l}\beta_{2} \text {-adrenergic agonist (by } \\
\text { nebulizer/compressor) }^{d}\end{array}$ & 86 \\
\hline $\begin{array}{l}\mathrm{H}_{1} \text {-antihistamine (any intravenous } \\
\text { formulation) })_{\mathrm{e}, \mathrm{e}}\end{array}$ & 77 \\
\hline $\begin{array}{l}\mathrm{H}_{2} \text {-antihistamine (any intravenous } \\
\text { formulation) }^{\dagger}\end{array}$ & 70 \\
\hline Glucagon & 73 \\
\hline Atropine & 73 \\
\hline \multicolumn{2}{|l|}{ Vasopressors in addition to epinephrine } \\
\hline Dopamine & 86 \\
\hline Noradrenaline & 70 \\
\hline Vasopressin & 64 \\
\hline All of the above medications available ${ }^{g}$ & 54 \\
\hline \multicolumn{2}{|c|}{$\begin{array}{l}\text { a For injection by any route (intramuscular [most common], subcuta- } \\
\text { neous, or intravenous [least common]). } \\
\text { b Medication, dose, and duration of treatment varied. } \\
\text { c Hydrocortisone or methylprednisolone. } \\
\text { d Albuterol (salbutamol) or levalbuterol. } \\
\text { e Chlorpheniramine, diphenhydramine, hydroxyzine, or promethazine. } \\
{ }^{f} \text { Cimetidine or ranitidine. } \\
{ }^{9} \text { Defined by expert opinion }{ }^{5,6,22-26} \text { as epinephrine, an intravenous } \\
\text { glucocorticoid, } \mathrm{H}_{1} \text {-antihistamine, } \mathrm{H}_{2} \text {-antihistamine, glucagon, atro- } \\
\text { pine, and } 1 \text { of dopamine, noradrenaline, or vasopressin; and a } \beta_{2}- \\
\text { adrenergic agonist for nebulization. }\end{array}$} \\
\hline
\end{tabular}

Table 3. Other Aspects of Acute Anaphylaxis Management

\begin{tabular}{|c|c|}
\hline Variable & $\begin{array}{l}\text { Responding } \\
\text { countries, \% } \\
(\mathrm{N}=43)\end{array}$ \\
\hline \multicolumn{2}{|l|}{ Management of the airway } \\
\hline Supplemental oxygen available & 95 \\
\hline \multicolumn{2}{|l|}{ Route of Delivery } \\
\hline Facemask & 79 \\
\hline Oropharyngeal airway & 66 \\
\hline Nasal prongs & 58 \\
\hline $\begin{array}{l}\text { Supplies and equipment available for } \\
\text { intubation }\end{array}$ & 89 \\
\hline Cricothyroidotomy & 36 \\
\hline \multicolumn{2}{|l|}{ Management of hypotension and shock } \\
\hline Intravenous fluids available & 98 \\
\hline \multicolumn{2}{|l|}{$\begin{array}{l}\text { Type of intravenous fluid given initially (ie, } \\
\text { during the first } 30 \text { minutes of treatment) }\end{array}$} \\
\hline Isotonic saline & 91 \\
\hline Lactated Ringer's solution & 42 \\
\hline Colloid & 12 \\
\hline \multicolumn{2}{|l|}{ Body position recommended } \\
\hline Back & 64 \\
\hline Position of comfort & 19 \\
\hline Side & 14 \\
\hline Sitting & 2 \\
\hline \multicolumn{2}{|l|}{ Monitoring in the health care setting ${ }^{a}$} \\
\hline $\begin{array}{l}\text { Frequent measurement of blood pressure } \\
\text { and heart rate by physician or nurse }\end{array}$ & 98 \\
\hline Pulse oximetry & 91 \\
\hline $\begin{array}{l}\text { Continuous noninvasive cardiac } \\
\text { monitoring }\end{array}$ & 81 \\
\hline Urine output & 74 \\
\hline
\end{tabular}

a The location in which the patients are monitored varies depending on the severity of the episode; however, in $48 \%$ of countries, this reportedly occurs in an emergency department or in an emergency department holding unit.

cocorticoid, antihistamines, glucagon, atropine, and 1 vasopressor in addition to epinephrine, as well as a $\beta_{2}$-agonist for nebulization), were available in $54 \%$ of the 44 responding countries (Table 2).

In most of the 43 responding countries, supplemental oxygen was reported to be available and was usually delivered by facemask at a rate of 6 to $8 \mathrm{~L} / \mathrm{min}$; also, supplies and equipment for intubation were available in $89 \%$ of these countries (Table 3). In addition, in most of the 43 countries, intravenous fluids were reported to be available for the management of hypotension and shock; for example, in more than $90 \%$ of these countries, rapid administration of a crystalloid, usually isotonic saline, was possible (Table 3 ).

In almost all of 43 responding countries, it was reported that monitoring of vital signs (eg, measurement of blood pressure using a sphygmomanometer and stethoscope) could be performed at intervals by health care professionals; however, supplies and equipment for continuous noninvasive monitoring of blood pressure and heart rate and pulse oximeters for measurement of oxygen saturation were not univer- 
sally available (Table 3 ). In most of the 43 countries, it was reported that patients were placed on the back or in a position of comfort during treatment of an acute anaphylaxis episode. In $63 \%$ of the countries, patients were kept in a physicianmonitored health care setting for at least 4 hours after the initial anaphylaxis symptoms resolved.

In most of the 44 responding countries, patients discharged from a health care setting after treatment of an acute anaphylaxis episode were reported to be equipped with epinephrine or a prescription for epinephrine to treat anaphylaxis recurrences in the community as an autoinjector, ampule with syringe, prefilled syringe, or metered-dose inhaler (Table 4). In half of the countries, some form of an anaphylaxis emergency action plan and some form of medical identification for patients stating their risk for anaphylaxis recurrence and their anaphylaxis trigger(s) were recommended (Table 4).

All tests considered to be necessary for confirming allergen sensitization and clinical risk of anaphylaxis recurrence, defined as skin prick tests, intradermal tests, allergen specific IgE measurement, and challenge or provocation tests, were reported to be available in $60 \%$ of the 44 responding countries (Table 5). Common triggers of anaphylaxis, also summarized in Table 5, were reported to include a wide variety of foods, medications, insect stings and bites, natural rubber latex, radiocontrast media and medical dyes, and allergen immunotherapy. Some triggers, such as Anisakis simplex and hydatid cyst, although uncommonly reported, were important considerations in specific geographic areas.

\section{DISCUSSION}

The results of this unique study reflect global availability of guidelines, medications, supplies, and equipment for the as-

Table 4. Preparing Patients for Anaphylaxis Recurrence in the Community

\begin{tabular}{lc} 
Variable & $\begin{array}{c}\text { Responding } \\
\text { countries, \% } \\
\text { (N = 44) }\end{array}$ \\
\hline $\begin{array}{l}\text { Medications at time of discharge from the } \\
\quad \text { health care setting }\end{array}$ & \\
Epinephrine/adrenaline (all formulations) & 91 \\
$\mathrm{H}_{1}$-antihistamine & 86 \\
Other aspects of discharge management & 53 \\
Anaphylaxis emergency action plan & 49 \\
Medical identification (eg. bracelet or card) & 51 \\
Chart sticker & 35 \\
Electronic chart flag &
\end{tabular}

a In 9\% of the countries, no epinephrine formulation was prescribed at discharge. In an additional $19 \%$ of the countries, epinephrine was available only in a metered-dose inhaler formulation (ie, could not be injected).

${ }^{b} \mathrm{~A}$ total of 13 different orally administered $\mathrm{H}_{1}$-antihistamines were recommended: 8 sedating first-generation medications (ie, chlorpheniramine, clemastine, dimethindene, diphenhydramine, hydroxyzine, ketotifen, pheniramine, and promethazine) and 5 nonsedating second-generation $\mathrm{H}_{1}$-antihistamines (ie, cetirizine, desloratadine, fexofenadine, levocetirizine, and loratadine)
Table 5. Tests and Triggers for Anaphylaxis

\begin{tabular}{cc}
\hline & Responding \\
Tests and triggers & countries, \% \\
& $(\mathrm{N}=44)$
\end{tabular}

Postdischarge availability of tests to confirm allergen sensitization ${ }^{a}$

Skin prick tests with allergen ${ }^{\mathrm{b}}$

Allergen specific IgE measurements in serum

Challenge or provocation tests ${ }^{c}$

Intradermal tests with allergen

All of the above tests (skin prick and intradermal tests, specific IgE levels, and challenge tests)

Triggers of anaphylaxis ${ }^{a}$

Medications $^{d}$

Foods, including spices and other additives ${ }^{e}$ Insect stings and bites ${ }^{f}$

Idiopathic (no trigger identified)

Radiocontrast media and medical dyes

Exercise, usually in association with food ingestion

Natural rubber latex

Allergen immunotherapy

Allergen skin tests

Anisakis simplex

Hydatid cyst

Other (vaccines to prevent infectious disease, seminal fluid, cosmetics, cold,

aeroallergens, eg, horse dander)

a Numbers add up to more than $100 \%$ because multiple triggers of anaphylaxis were reported from all countries

b Skin prick tests used for foods, venoms, medications (including local anesthetics), latex, airborne allergens, Anisakis simplex, and radiocontrast media.

${ }^{c}$ Challenge and provocation tests used for foods, medications, local anesthetics, Hymenoptera venoms, and exercise.

d Medication triggers included $\beta$-lactam antibiotics (penicillin, ampicillin, cloxacillin, ceftriaxone and other cephalosporins, and quinolones) and antibiotics from other classes, including sulfas and antituberculosis drugs, such as streptomycin; anticancer drugs (taxanes, platins, and monoclonal antibodies, such as cetuximab); other monoclonal antibodies, such as infliximab and omalizumab; central nervous system drugs, including anticonvulsants, drugs for insomnia (sedatives), opioids, analgesics, and antipyretics, including nonsteroidal anti-inflammatory drugs, such as acetylsalicylic acid, paracetamol (acetaminophen), and dipyrone; neuromuscular blockers, general anesthetics; local anesthetics; proton pump inhibitors; and vitamins.

e Food triggers included peanut and other legumes, including chickpea (Bengal gram) and lentils (eg, urad dhal); all tree nuts, including hazelnut, cashew, and walnut; shellfish, including shrimp, crab, and mollusks; finned fish, including sheatfish and hilsha fish; cow's milk; goat's milk; egg; seeds, including sesame and sunflower; fresh fruits, including peach, kiwi, apple, pineapple, pomegranate, citrus fruits, and exotic fruits; vegetables, including celery and eggplant; cereals and grains, including wheat and buckwheat; meat, including chicken and beef; and other, including soy, spices, mugwort, bird's nest soup, and honey.

${ }^{f}$ Insect sting or bite triggers included Hymenoptera species (eg, honeybees, bumblebees, wasps, yellow jackets, hornets, ants [fire, harvester, jumper, red]) and Diptera species (eg, mosquitoes and aphids) and the arachnids spiders and scorpions. 
sessment and management of anaphylaxis in health care settings, as reported in 2008 by representative allergy-immunology specialists from 44 countries, identified through the WAO House of Delegates.

\section{Anaphylaxis Definitions and Guidelines}

Allergy-immunology specialists reported use of modern, broad definitions of anaphylaxis, predominantly the WAO definition, ${ }^{1}$ the identical EAACI definition, ${ }^{2}$ or the NIAID/ FAAN definition that is accompanied by detailed criteria for making the clinical diagnosis of anaphylaxis. ${ }^{3}$ In these definitions, no distinction is made between anaphylaxis that occurs through immunologic mechanisms (commonly through $\operatorname{IgE}$ and the high-affinity Fce receptor and, rarely, through other immunologic mechanisms) and anaphylaxis that occurs through nonimmunologic mechanisms. Hypotension or shock are not necessarily present. The term anaphylactoid is no longer recommended for use.

National anaphylaxis guidelines were reported to be in used in $36 \%$ of responding countries..$^{5-14}$ Guidelines developed by medical professional societies in countries other than the responder's own country, most commonly the American Academy of Allergy Asthma and Immunology/American College of Allergy, Asthma and Immunology guidelines, ${ }^{5}$ Resuscitation Council UK guidelines, ${ }^{6}$ or the Australasian Society of Clinical Immunology and Allergy guidelines, ${ }^{7}$ were reported to be in use in $34 \%$ of countries. Of all the guidelines reported to be in use, few were evidence based, ${ }^{5}$ and only a few were published in indexed peer-reviewed journals $5^{5-8}$ and could therefore be readily identified in a medical literature search.

In a previous systematic literature search performed by epidemiologists, only 6 countries in the world were identified as having national anaphylaxis guidelines. ${ }^{15}$ Some of these guidelines were descriptive reviews that did not have the endorsement of a national allergy society, most did not make clear the strength of the evidence behind the recommendations made, and there were important differences in many of the recommendations. ${ }^{15}$ The development of anaphylaxis guidelines is, however, a dynamic, ongoing process. Since completion of the 2008 WAO survey of essentials for the assessment and management of anaphylaxis that is reported here, additional national guidelines have been developed, and additional regional guidelines have been published in indexed peer-reviewed journals. ${ }^{16}$

\section{Diagnosis of an Acute Anaphylaxis Episode}

The diagnosis of an acute anaphylaxis episode was reported to be based on clinical history and physical findings alone in most countries. Laboratory tests, such as measurement of serum total tryptase levels or plasma and urine histamine levels, to confirm the clinical diagnosis were not widely available. This is not necessarily a major concern unless physicians fail to diagnose anaphylaxis in the absence of a supporting laboratory test result.
The use of elevated tryptase or histamine levels to confirm the diagnosis of anaphylaxis is not a component of any anaphylaxis definition ${ }^{1-3}$; in addition, elevations in tryptase or histamine levels are not specific for anaphylaxis. ${ }^{17,18}$ The diagnosis of anaphylaxis depends primarily on the history of exposure to a potential triggering agent or event, the brief time elapsed (minutes to several hours) between exposure and symptom onset, ${ }^{3}$ the rapid evolution of symptoms and signs, and recognition of the pattern of target organ involvement with approximately 40 different cutaneous, respiratory, gastrointestinal, cardiovascular, and/or central nervous system symptoms. ${ }^{3,17,18}$

Even in countries where measurements of tryptase levels or histamine levels are readily available in clinical laboratories, these assays take several hours to perform, and results are seldom, if ever, available on an emergency basis. In addition, even when tryptase or histamine levels are measured in a timely manner under optimal conditions, the levels are not necessarily elevated in all patients with a clinical diagnosis of anaphylaxis; for example, tryptase levels are seldom elevated in normotensive patients or anaphylaxis triggered by food. Moreover, tryptase and histamine levels that are within normal limits cannot be used to refute the diagnosis of anaphylaxis. ${ }^{3,17,18}$

\section{Treating and Monitoring an Acute Anaphylaxis Episode}

Epinephrine (adrenaline) in ampules for injection by any route was the only medication that was universally available for anaphylaxis treatment. This reflects the World Health Organization position that epinephrine is an essential medication for anaphylaxis treatment (www.who.int) and also reflects the recommendations in anaphylaxis guidelines ${ }^{5-16}$ and previous WAO anaphylaxis publications ${ }^{19-21}$ that prompt injection of epinephrine (adrenaline) is the initial medication of choice in anaphylaxis.

Intravenous formulations of 1 or more glucocorticoids, $\mathrm{H}_{1}$-antihistamines, $\mathrm{H}_{2}$-antihistamines, and $\beta_{2}$-adrenergic agonists for administration by nebulizer were not universally available worldwide. Anaphylaxis guidelines vary in their recommendations for use of these ancillary medications..$^{5-15}$ Several different $\mathrm{H}_{1}$-antihistamines for intravenous administration are recommended in varying doses for various lengths of time. Several different glucocorticoids for intravenous administration are recommended in varying doses for various lengths of time. $\mathrm{H}_{2}$-antihistamines and vasopressors in addition to epinephrine (adrenaline), such as dopamine, noradrenaline, or vasopressin, are not listed in some guidelines. ${ }^{15}$ Nevertheless, based on decades of clinical use, consensus opinion, and systematic reviews of the literature to date, all of these medication classes are currently considered to play a role in the treatment of anaphylaxis..$^{5-17,22-25}$ Many of the medications in these classes were, like epinephrine, introduced for the treatment of anaphylaxis before the era of randomized controlled trials and evidence-based medicine. Whether they are truly essential will remain unknown until 
they are prospectively studied in randomized controlled trials in anaphylaxis. ${ }^{26}$

Lack of availability of glucagon is a concern for patients who are taking $\beta$-adrenergic blockers and might not respond to epinephrine. Lack of availability of atropine is a concern for patients with anaphylaxis who develop bradycardia rather than the more typical tachycardia. Inability to administer epinephrine (adrenaline) by slow intravenous infusion or to give intravenous dopamine, noradrenaline, or vasopressin is a concern in patients with anaphylaxis that is refractory to intramuscular epinephrine injections., ${ }^{3,5-7}$

The question has been raised, however, of whether intravenous infusion of potent vasopressors should be considered to be within the scope of expertise of all allergy-immunology specialists, particularly those working in community-based clinics and medical offices. This is particularly true in settings where infusion pumps are not available and where dose titration against blood pressure, heart rate and function, and oxygenation as determined by using continuous noninvasive monitoring is not possible because of a lack of the requisite supplies, equipment, and experienced health care professionals. ${ }^{6,7}$ Few national anaphylaxis guidelines provide recommendations about monitoring patients with anaphylaxis; one guideline suggests that, at a minimum, noninvasive continuous blood pressure and heart rate monitoring, ability to take a 3-lead electrocardiogram, and pulse oximetry are necessary. ${ }^{6}$

\section{Essentials for Anaphylaxis Assessment and Management}

On the basis of the survey results reported here and on existing anaphylaxis guidelines, ${ }^{5-16}$ the essentials needed for appropriate assessment and treatment of patients with anaphylaxis include having a guideline (plan) and making the clinical diagnosis of anaphylaxis promptly on the basis of the clinical history, symptoms, and signs. Promptly and simultaneously place a call for help to a resuscitation team or emergency medical services, whichever is appropriate and available, inject epinephrine (adrenaline) intramuscularly, and place the patient on his/her back or in a position of comfort with the lower extremities elevated. Then, start supplemental oxygen treatment, intravenous fluids, and cardiopulmonary resuscitation immediately, if indicated.,5-17

In areas where resources are limited, it is particularly important to ensure that epinephrine (adrenaline) is injected intramuscularly as soon as anaphylaxis is recognized because the initial first-aid dose of $0.01 \mathrm{mg} / \mathrm{kg}$ is low compared with the dose for cardiopulmonary resuscitation, and if injected late in patients with cardiorespiratory failure or shock, it is likely to be ineffective. ${ }^{27-32}$ The epinephrine dose can be repeated several times, every 5 to 15 minutes, if needed. ${ }^{19}$

\section{Follow-up of Patients After Treatment of an Acute} Anaphylaxis Episode

The survey findings suggest that preparing and equipping patients at risk for recurrence of anaphylaxis in community settings $^{5-7,17,33}$ is not yet a high priority in many countries.
Although epinephrine (adrenaline) was commonly prescribed at discharge after resolution of the acute anaphylaxis episode, it was often recommended or supplied in suboptimal formulations, such as an ampule with a syringe, a prefilled syringe, or a metered-dose inhaler, ${ }^{34-36}$ rather than an autoinjector. This is consistent with the findings of 2 previously published WAO surveys and probably relates to lack of availability and affordability of epinephrine autoinjectors. ${ }^{20,21}$

The survey findings reported in this article also indicate that many allergy-immunology specialists do not have all the necessary materials, supplies, and equipment available to confirm sensitization to allergens identified in the history as potential triggers of anaphylaxis. This follow-up is important to provide appropriate long-term management, specifically, to provide each patient with personalized information about avoidance of specific allergens and, where indicated, relevant immunomodulation to reduce the likelihood of recurrent anaphylaxis episodes. ${ }^{18,37,38}$

\section{Limitations of this Survey}

The new information reported in this article likely represents a best-case scenario among and within countries because the responses were received from representative leading allergyimmunology physicians in WAO member countries where this specialty is established or is becoming established. The availability of essentials for the assessment and management of anaphylaxis is unknown in the nonresponding WAO member countries, most of which are designated as low-resource countries by the World Bank (www.worldbank.org) and in the many countries that are not yet represented in the WAO because they have few or no allergy-immunology specialists. Also, in the responses to this survey, there were unsolicited comments about inconsistent availability of medications in a country, medications being available but not necessarily within the expiry dates, and the necessity to clean and reuse supplies intended for disposal after a single use.

An important question that needs to be addressed is whether more information, or more reliable information, about essentials in anaphylaxis might have been obtained using different approaches from the one reported here. Two alternative possibilities were considered. An independent attempt could have been made to contact each of the allergyimmunology organizations worldwide; however, this might have resulted in overrepresentation of countries where the specialty is well established and underrepresentation of countries where it is becoming established because of potential difficulties in identifying and contacting colleagues in the latter countries. A systematic literature search for anaphylaxis guidelines could have been performed; however, as noted previously, the results of a search published in $2007^{15}$ suggested that few such guidelines would be retrieved by this method because few have been published in indexed peerreviewed medical journals. Indeed, this has been confirmed by the study reported here. It is therefore likely that the method of sampling used, specifically, obtaining information 
from allergy-immunology specialists as identified through the WAO House of Delegates, was a reasonable one.

\section{Implications}

Lack of availability of the necessary medications, supplies, and equipment in many countries might mean the difference between life and death for residents and travelers who experience anaphylaxis in these countries. Improved worldwide availability of life-saving essentials for assessment and management of anaphylaxis is needed. The global anaphylaxis guidelines being developed by the WAO will provide information about the basic medications, supplies, and equipment that are absolutely necessary for assessment and management, as well as those that are optimal.

\section{ACKNOWLEDGMENTS}

I sincerely acknowledge the support of the WAO Executive Committee (Professors Walter Canonica, Richard Lockey, Jean Bousquet, Ruby Pawankar, Michael Kaliner, and Carlos Baena-Cagnani) and the WAO Secretariat. I am grateful to all the WAO members who contributed to this project, including Professors Stephen Betschel, Beatrice Bilo, Yuriy Bisyuk, Victoria Cardona, Hiok Hee Chng, Ronald Dahl, Hans deGroot, Vojislav Djuric, Diana Dumitrascu, Stephen Durham, Yehia El-Gamal, Angela Gaspar, Sandra Gonzalez-Diaz, Kamal Hanna, Rashidul Hassan, Yin Jia, Omer Kalayci, Ranbir Kaulsay, Rakhim Khaitov, Kalliopi Kontou-Fili, Krzysztof Kowal, Petr Kucera, Le Thi Tuyet Lan, Bjorn Luoviksson, Hee-Bom Moon, Cas Motala, Takemasa Nakagawa, Kristof Nekam, Mahesh Padukudru, Todor Popov, Nagendra Prasad, Fabienne Rance, Nelson Rosario, Lanny Rosenwasser, Menachem Rottem, Mario Sanchez-Borges, Joaquin Sastre, Peter Schmid-Grendelmeier, Juan Schuhl, Revaz Sepiashvili, Aziz Sheikh, Paolo Tassinari, Nualanong Visitsunthorn, Bettina Wedi, and Fares Zaitoun. I appreciate the assistance of Ilona V. DuBuske, RN, who assisted with translations. I thank Lori McNiven and Mary Cheang, M Math (Stat), at the Health Sciences Centre/University of Manitoba, Winnipeg, Manitoba, Canada, for their dedication to this project. The WAO acknowledges the unrestricted anaphylaxis education grant provided by UCB Pharma for this project.

\section{REFERENCES}

1. Johansson SGO, Bieber T, Dahl R, et al. Revised nomenclature for allergy for global use: report of the Nomenclature Review Committee of the World Allergy Organization, October 2003. J Allergy Clin Immunol. 2004;113:832-836.

2. Johansson SG, Hourihane JO, Bousquet J, et al. A revised nomenclature for allergy: an EAACI position statement from the EAACI nomenclature task force. Allergy. 2001;56:813-824.

3. Sampson HA, Munoz-Furlong A, Campbell RL, et al. Second symposium on the definition and management of anaphylaxis: summary report: Second National Institute of Allergy and Infectious Disease/Food Allergy and Anaphylaxis Network symposium. J Allergy Clin Immunol. 2006;117:391-397.

4. Lieberman P, Camargo CA Jr, Bohlke K, et al. Epidemiology of anaphylaxis: findings of the American College of Allergy, Asthma and Immunology Epidemiology of Anaphylaxis Working Group. Ann Allergy Asthma Immunol. 2006;97:596-602.
5. Joint Task Force on Practice Parameters, American Academy of Allergy Asthma and Immunology, American College of Allergy Asthma and Immunology, Joint Council of Allergy Asthma and Immunology. The diagnosis and management of anaphylaxis: an updated practice parameter. J Allergy Clin Immunol. 2005;115:S483-S523.

6. Soar J, Pumphrey R, Cant A, et al. Emergency treatment of anaphylactic reactions: guidelines for healthcare providers. Resuscitation. 2008;77: 157-169.

7. Brown SGA, Mullins RJ, Gold MS. Anaphylaxis: diagnosis and management. Med J Aust. 2006;185:283-289.

8. Malling H-J, Hansen KS. Anafylaksi [Anaphylaxis]. Ugeskr Laeger. 2005; 167:664-666.

9. Rancé F. Traitement du choc et bon usage de l'adrénaline. Rev Fr Allergol Immunol Clin. 2004;44:336-341.

10. Emergency treatment of anaphylactic reactions. Allergo J. 2007;6: $420-434$

11. Bernd LAG, Sole D, Pastorino AC, et al. Anafilaxia: guia pratico para o manejo. Rev Bras Alerg Imunopatol. 2006;29:283-291.

12. Comité de Alergia e Inmunología. Normativa para el tratamiento del choque anafilactico. Arch Arg Pediatr. 1998;96:272.

13. Ring J, Brockow K, Duda D, et al. S2-Leitlinie akuttherapie anaphylaktischer reaktionen. Allergologie. 2007;30:469-486.

14. Perino A, Galimberti M, Bilo MB, Asero R, Pezzuto F. Use of adrenaline in allergy. Eur Ann Allergy Clin Immunol. 2008;40:35-52.

15. Alrasbi M, Sheikh A. Comparison of international guidelines for the emergency medical management of anaphylaxis. Allergy. 2007;62: $838-841$.

16. Muraro A, Roberts G, Clark A, et al. The management of anaphylaxis in childhood: position paper of the European Academy of Allergology and Clinical Immunology. Allergy. 2007;62:857-871.

17. Simons FER. Anaphylaxis: recent advances in assessment and treatment. J Allergy Clin Immunol. 2009;124:625-636.

18. Simons FER, Frew AJ, Ansotegui IJ, et al. Risk assessment in anaphylaxis: current and future approaches. J Allergy Clin Immunol. 2007;120:S2-S24

19. Kemp SF, Lockey RF, Simons FER. Epinephrine: the drug of choice for anaphylaxis: a statement of the World Allergy Organization. Allergy. 2008;63:1061-1070.

20. Simons FER, for the World Allergy Organization. Epinephrine autoinjectors: first-aid treatment still out of reach for many at risk of anaphylaxis in the community. Ann Allergy Asthma Immunol. 2009;102: 403-409.

21. Simons FER. Lack of worldwide availability of epinephrine autoinjectors for outpatients at risk of anaphylaxis. Ann Allergy Asthma Immunol. 2005;94:534-538.

22. Sheikh A, Shehata YA, Brown SGA, Simons FER. Adrenaline for the treatment of anaphylaxis: Cochrane systematic review. Allergy. 2009; 64:204-212.

23. Sheikh A, Ten Broek V, Brown SGA, Simons FER. $\mathrm{H}_{1}$-antihistamines for the treatment of anaphylaxis: Cochrane systematic review. Allergy. 2007;62:830-837.

24. Choo KJL, Simons FER, Sheikh A. Glucocorticoids for the treatment of anaphylaxis (protocol). Cochrane Database Syst Rev. 2009;1: CD007596.

25. Mullner M, Urbanek B, Havel C, Losert H, Waechter F, Gamper G. Vasopressors for shock. Cochrane Database Syst Rev. 2004;3: CD003709.

26. Simons FER. Emergency treatment of anaphylaxis. BMJ. 2008;336: 1141-1142.

27. Sampson HA, Mendelson L, Rosen JP. Fatal and near-fatal anaphylactic reactions to food in children and adolescents. $N$ Engl J Med. 1992;327: 380-384.

28. Bock SA, Munoz-Furlong A, Sampson HA. Fatalities due to anaphylactic reactions to foods. J Allergy Clin Immunol. 2001;107:191-193.

29. Pumphrey RSH. Lessons for management of anaphylaxis from a study of fatal reactions. Clin Exp Allergy. 2000;30:1144-1150. 
30. Bock SA, Munoz-Furlong A, Sampson HA. Further fatalities caused by anaphylactic reactions to food, 2001-2006. J Allergy Clin Immunol. 2007;119:1016-1018.

31. Pumphrey RSH, Gowland MH. Further fatal allergic reactions to food in the United Kingdom, 1999-2006. J Allergy Clin Immunol. 2007;119: 1018-1019.

32. Greenberger PA, Rotskoff BD, Lifschultz B. Fatal anaphylaxis: postmortem findings and associated comorbid diseases. Ann Allergy Asthma Immunol. 2007;98:252-257.

33. Nurmatov U, Worth A, Sheikh A. Anaphylaxis management plans for the acute and long-term management of anaphylaxis: a systematic review. J Allergy Clin Immunol. 2008;122:353-361.

34. Simons FER, Chan ES, Gu X, Simons KJ. Epinephrine for the out-ofhospital (first aid) treatment of anaphylaxis in infants: is the ampule/ syringe/needle method practical? J Allergy Clin Immunol. 2001;108: 1040-1044.

35. Rawas-Qalaji M, Simons FER, Collins D, Simons KJ. Long-term stability of epinephrine dispensed in unsealed syringes for the first-aid treatment of anaphylaxis. Ann Allergy Asthma Immunol. 2009;102: $500-503$

36. Simons FER, Gu X, Johnston L, Simons KJ. Can epinephrine inhalations be substituted for epinephrine injection in children at risk for systemic anaphylaxis? Pediatrics. 2000;106:1040-1044.

37. Sampson HA, Sicherer H. Food allergy: primer on allergic and immunologic diseases. J Allergy Clin Immunol. 2010;125:S116-S125.

38. Bilo MB. The natural history and epidemiology of insect venom allergy: clinical implications. Clin Exp Allergy. 2009;39:1467-1476.

Requests for reprints should be addressed to:

F. Estelle R. Simons, MD, FRCPC

Room FE125

820 Sherbrook $S t$

Winnipeg, Manitoba, Canada R3A $1 R 9$

E-mail:Imcniven@hsc.mb.ca

Answers to CME examination-Annals of Allergy,

Asthma \& Immunology, February 2010 Tilles SA: Ex-

ercise-induced respiratory symptoms: an epidemic among adolescents. Ann Allergy Asthma Immunol. 2010;104:361367.
1. c
2. $\mathrm{b}$
3. e
4. e
5. c 